\title{
Menopause Hormone Therapy Current Evidence and Clinical Use
}

\author{
BaquedanoL $^{1,2 *}$, LaprestaM ${ }^{2}$ and Colmenarejo $\mathrm{F}^{2}$ \\ ${ }^{1}$ Hospital Universitario Miguel Servet, Zaragoza, Spain \\ ${ }^{2}$ Hospital Quironsalud, Zaragoza, Spain
}

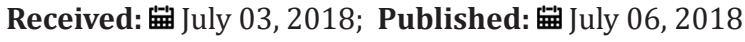

*Corresponding author: Laura BaquedanoMainar, Ginecology Department, Hospital Quironsalud, Zaragoza, Spain, Tel:+43652025406; Email: lbaquedanome@hotmail.com

Abbreviations: MHT: Menopause Hormone Therapy; VSM: Vasomotor Symptoms; CEE: Conjugated Equine Estrogens; MPA: Medroxy Progesterone Acetate; WHI: Women's Health Initiative; BZA: Bazedoxifene; TSEC: Tissue-Selective Estrogen Complex; EMA: European Medicines Agency; FDA: US Food and Drug Administration

\section{Short Comunication}

Spontaneous menopause, the permanent cessation of menstruation caused by loss of ovarian function, occurs at a mean age of 51-52 years. As life expectancy increases,women are living far longer after menopauseonset than in the past.Climacteric syndrome is common but it is not always necessary to treat women in the transition and in menopause. However, hormonal changes can be associated with symptoms; the most common are hot flashes and night sweats. Others like dyspareunia, vaginal dryness, mood swings and sexual dysfunction can frequently appear. There is an increase in bone resorption on occasions leading toosteopenia and osteoporosis. Women who are severely symptomatic, $25-30 \%$ of all menopause women, have their quality of life affected [1]. In addition to this deleterious effect, menopausal womenalso have an increased prevalence of coronary heart disease and obesity [2].Menopause hormone therapy (MHT) is the most effective treatment for symptoms. It is the gold standard for relievingvasomotorsymptoms (VSM) and also it improves other problems related with menopause. Furthermore, MHT is effective in preventing the loss of bone massand in reducing cardiovascular accident [3]. Thus, there is a global consensus statement on MHT that concluded that for symptomatic women the benefits are higher than risks before 60 years old or within 10 years after menopause [4-6].

The most prescribed therapy for menopause in the USA was a combination of conjugated equine estrogens (CEE) plus medroxyprogesterone acetate (MPA) but breast cancer risk was a major safety concern with this regimen.The Women's Health Initiative (WHI) was a randomized, controlled trial study designed to determine the benefits and risks of MHT taken for chronic disease prevention by healthy postmenopausal women. The study ended early due to findings of increased relative risk of breast cancer after
5.2 years of treatment [6]. CEE alone did not increase the risk of breast cancer in the WHI study, and after 7 years of intervention, it reduced breast cancer risk at the 6year follow-up [7]. In 2016 the WHI authors wrote a paper explaining maybe there was a mistake in the interpretation of this study; they remarked the possible role of the progesterone in increasing the risk of breast cancer and stimulated the need to develop safer alternatives [8]. Furthermore, in 2017 they published a study concluding MHT was associated with lower mortality from all causes after 18 years of follow-up of WHI study patients[9].

\section{Formulation, Dosing, Route of Administration}

It is necessary to individualize the treatment for each patient, according to the clinic, tolerance, personal preferences, age, and time of menopause, co morbidities and risks.

\section{Formulations}

Estrogens:The estrogens most commonly prescribed are CEE, synthetic conjugated estrogens and micronized $17 \mathrm{~b}$-estradiol. CEE, used in theWHI, is isolated from the urine of pregnant mares andcomprised of estrone sulfate (weaker than estradiol) andmixtures of more than 10 minor components of differentactive forms of estrogens (weak estrogen agonists). CEE and estradiol are metabolizedinto weaker estrogens such as estrone. Thus, there may bedifferences in the types of concentrations of estrogens orinteractions with estrogen receptors in different target tissues [4].Meta-analysis of estrogen trials found noevidence of a significant difference in effectiveness betweenestradiol and CEE in treating VMS [10].However, there were differencesin cognitive outcomes andthe brain serotonergic system, with estradiol providing morerobust anxiolytic and antidepressant effects [11]. 
Progesterone:The indication for progesteroneuse is to prevent endometrial overgrowth and the increasedrisk of endometrial cancer with estrogen treatment.Progestins commonlyused include MPA, norethindrone acetate, and nativeprogesterone [4].A higher incidence of breast cancer was seen in theWHI for CEE and MPA compared with placebo [6]. Conversely others studies havesuggested that the risk of breast cancer may be less withthe use of micronized progesterone[12].

Tissue-Selective Estrogen Complex (TSEC):TSEC is a innovative, alternative treatment which combines CEE and a selective estrogen receptor modulator, bazedoxifene (BZA) rather than a progesterone for uterine protection.The reason for this combination was to blend the anti-estrogen effects on the uterus and breast of BZA, maintaining the positive estrogenic effects in VMS, vaginal symptoms and skeletal bone mass, without the need of progesterone. This combinationis the first TSEC approved, by the FDA (US Food and Drug Administration) and EMA (European Medicines Agency) $[13,14]$.

Dosing:The therapeutic goal should be to use the effective dose to achieve the relief of menopausal symptoms.The appropriate dose of progestogen is addedto provide endometrial protection if the woman has a uterus,unless CEE is combined with bazedoxifene.

Routes of Administration:The route of administration of THM should be chosen taking into account the pharmacokinetics, clinical characteristics of each route and the preferences of women to ensure adherence.Systemic estrogens can be prescribed as oral pills, transdermalpatches, sprays, and gels.Transdermalestradioltransfer bioactive hormonedirectly into the subcutaneous microcirculation provides safety advantages over traditional oraltherapy: there isno first-pass hepatic transformation and it has little or no effecton clotting factors, lipoproteins, sex hormone bindingglobulin, hepatic enzymes, or C-reactive protein $[15,16]$. There are reports that concluded there is alittle or no increase in thromboembolic events (TEE) withtransdermal estradiol $[17,18]$. Therefore it is the route of first choice in women with risk of TEE, such as overweight, smokers or sedentary patients.Progesterone's are available asoral drugs, combination patches with estrogen, intrauterinesystems, injectables, and vaginal capsules.

\section{References}

1. Gjelsvik B, Rosvold EO, Straand J, Dalen I, Hunskaar S (2011) Symptom prevalence during menopause and factors associated with symptoms and menopausal age. Results from the Norwegian Hordaland Women's Cohort study. Maturitas 70(4): 383-90.

2. Dennis KE (2007) Post menopausal women and the health consequences of obesity. J Obstet Gynecol Neonatal Nurs 36(5): 511-519.
3. Ramezani Tehrani F, Behboudi Gandevani S, Ghanbarian A, Azizi F (2014) Effect of menopause on cardiovascular disease and its risk factors: a9year follow-up study. Climacteric 17(2): 164-172.

4. (2017) The 2017 hormone therapy position statement of The North American Menopause Society Menopause. The NAMS 2017 Hormone Therapy Position Statement Advisory Panel. Menopause 24(7): 728-753.

5. Baber RJ, Panay N, Fenton A, IMS Writing Group (2016) IMS Recommendations on women's midlife health and menopause hormone therapy. Climacteric 19(2): 109-150.

6. Rossouw JE, Anderson GL, Prentice RL, La Croix AZ, Kooperberg C, et al. (2002) Risks and benefits of estrogen plus progestin in healthy postmenopausal women: principal results From the Women's Health Initiative randomized controlled trial. JAMA 288(3): 321-333.

7. Manson JE, Chlebowski RT, Stefanick ML, Aragaki AK, Rossouw JE, et al. (2013) Menopausal hormone therapy and health outcomes during the intervention and extended post stopping phases of the Women's Health Initiative randomized trials. JAMA 310(13): 1353-1368.

8. Manson JE, Kaunitz AM (2016) Menopause Management--Getting Clinical Care Back on Track. N Engl J Med. 374(9): 803-806.

9. Manson JE, Aragaki AK, Rossouw JE, Anderson GL, Prentice RL, et al. (2017) Menopausal Hormone Therapy and Long-term All-Cause and Cause-Specific Mortality: The Women's Health Initiative Randomized Trials. JAMA 318(10): 927-938.

10. Gaudard AM, Silva de Souza S, Puga ME, Marjoribanks J, da Silva EM, et al. (2016) Bioidentical hormones for women with vasomotor symptoms. Cochrane Database Syst Rev 8: CD010407.

11. Gleason CE, Dowling NM, Wharton W, Manson JE, Miller VM, et al. (2015) Effects of hormone therapy on cognition and mood in recently postmenopausal women: findings from the randomized, controlled KEEPS-Cognitive and Affective Study. PLoS Med 12(6): e1001833.

12. Fournier A, Mesrine S, Dossus L, Boutron Ruault MC, Clavel Chapelon F, et al. (2014) Risk of breast cancer after stopping menopausal hormone therapy in the E3N cohort. Breast Cancer Res Treat 145(2): 535-543.

13. http://www.ema.europa.eu/docs/es_ES/document_library/EPAR_ Product_Information/human/002314/WC500181566.pdf.

14. (2003) FDA Guidance: Estrogen and Estrogen/Progestin Drug Products to Treat Vasomotor Symptoms and Vulvar and Vaginal Atrophy Symptoms-Recommendations for Clinical Evaluation.

15. Kuhl H (2005) Pharmacology of estrogens and progestogens: influenceof different routes of administration. Climacteric 8(suppl 1): 3-63.

16. Schmidt JW, Wollner D, Curcio J, Riedlinger J, Kim LS (2006) Hormone replacement therapy in menopausal women: past problems and future possibilities. Gynecol Endocrinol 22(10): 564-577.

17. Canonico M,Oger E, Plu Bureau G, Conard J, Meyer G, etal. (2007) Hormone therapy and venous thrombo embolism among postmenopausal women: impact of the route of estrogen administration and progesterone's: the ESTHER study. Circulation 115(7): 840-845.

18. Canonico M, Plu Bureau G, Lowe GD, Scarabin PY (2008) Hormone replacement therapy and risk of venous thromboembolism in postmenopausal women: systematic review and meta-analysis. BMJ 336 (7655): 1227-1231. 
(C) (1) This work is licensed under Creative

To Submit Your Article Click Here: Submit Article

DOI: $10.32474 /$ IGWHC.2018.02.000134

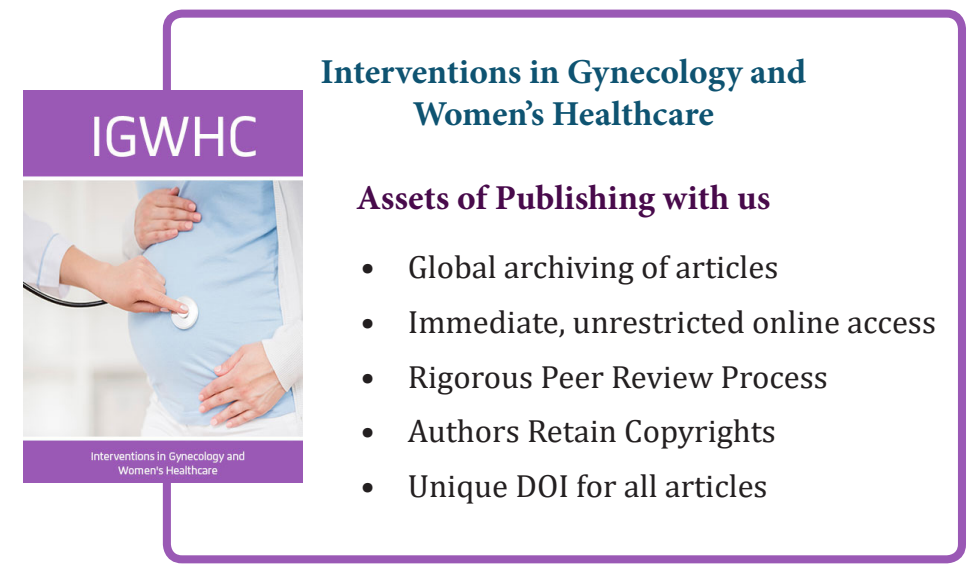

